\title{
A IDENTIDADE HISTÓRICO CULTURAL DE SÃO PAULO POR MEIO DE SUA NARRATIVA IDENTITÁRIA: A CIDADE DO TRABALHO E DO ENTRETENIMENTO
}

\author{
Recebido em: 24/04/2014
}

Aceito em: 01/10/2014

Alexandre Leonarde ${ }^{1}$

$\mathrm{EACH}-\mathrm{USP}$

São Paulo - SP - Brasil

RESUMO: O artigo estuda a identidade cultural da cidade de São Paulo, assumindo-a como dinâmica e aberta, não fixa e não permanente, caracterizada pela multiplicidade. Para captar tais identidades, sem referenciais estáveis, analisou-se sua narrativa identitária, o que permitiu captar como a cidade é imaginada, revelando suas múltiplas identidades. Na perspectiva histórica, a identidade cultural da cidade foi vinculada à velocidade, ao trabalho e ao progresso. Porém, em São Paulo nas últimas décadas, o entretenimento vem ganhando relevância econômica, espaço nos meios de comunicação, é importante empreendimento econômico, meio de sua promoção turística, por fim, compondo sua narrativa identitária, sendo considerado, no tempo presente, como mais um elemento da identidade cultural da cidade de São Paulo.

PALAVRAS CHAVE: Atividades de Lazer. Turismo. Características Culturais.

\section{THE HISTORICAL, CULTURAL IDENTITY OF SÃO PAULO THROUGH ITS NARRATIVE IDENTITY: THE CITY OF WORK AND ENTERTAINMENT}

ABSTRACT: The article addresses the cultural identity of the city of São Paulo, assuming it is dynamic and open, not fixed and not permanent, characterized by its multiplicity. In order to grasp the city's multiple identities, and in view of the absence of solid references, this study analyzed its narrative identity, which allow us to grasp how the city is imagined, thus revealing its multiple identities. In a historical perspective, the city's identity has been linked to speed, work, and progress. However, entertainment in São Paulo has been gaining economic relevance and space in the media over the past decades, and it has become an important economic enterprise and a means to promote tourism in the city, composing the city's identitarian narrative and might even be considered an extra element comprising the cultural identity of the city of São Paulo nowadays.

KEYWORDS: Leisure Activities. Tourism. Cultural Characteristics.

\footnotetext{
${ }^{1}$ Pós-doutorando em Lazer e Turismo na Escola de Artes, Ciências e Humanidades, da Universidade de São Paulo (EACH-USP). Membro do Grupo Interdisciplinar de Estudos do Lazer (GIEL-EACH-USP). Bolsista Pós-doutorado Júnior CNPq.
} 


\section{Introdução}

O presente estudo tem seu ponto de partida na percepção de um significativo crescimento das atividades de entretenimento na cidade de São Paulo nos últimos anos, particularmente as relacionadas à gastronomia, bares, cinemas, teatros e casas noturnas. Segundo a Associação Brasileira de Bares e Restaurantes - Abrasel e a São Paulo Turismo - Spturis ${ }^{2}$, empresa municipal de promoção do turismo e eventos, a cidade possui 12,5 mil restaurantes, 16 mil bares, 260 salas de cinema, 181 teatros, com cerca de 600 peças encenadas por ano - destas pelo menos dez são versões nacionais de musicais da Broadway -, 2 mil casas noturnas e incontáveis eventos culturais variados. O que faz de São Paulo a segunda cidade do mundo com maior número de estabelecimentos do gênero, ficando atrás apenas de Nova Iorque (SÃO PAULO, 2010).

As atividades de entretenimento, ao longo da história da cidade de São Paulo, vem sendo incorporadas ao imaginário de seus habitantes, merecendo atenção da academia, engendrando formas próprias de ocupação e fruição do espaço urbano (MAGNANI, 2007), tornando-se um setor com grande peso na economia da cidade. É possível, no tempo presente, conjecturar, por exemplo, por meio de dados relativos à economia do entretenimento, que sua fruição é parte dos hábitos e costumes de um número crescente de paulistanos, projetando seu impacto para além do campo econômico, tornando-o um elemento da identidade cultural da cidade, perceptível por meio da análise de sua narrativa identitária, aqui, revelada em sua história, literatura, música, cinema e meios de comunicação, fornecendo, como indica Hall (2006), uma série de histórias, imagens, panoramas, cenários, eventos históricos, símbolos e rituais

\footnotetext{
${ }^{2}$ Disponível em: $<$ http://www.cidadedesaopaulo.com/sp/br/sao-paulo-em-numeros $>$. Acesso em: 11 mar. 2012.
} 
que representam as experiências partilhadas e que dão sentido à cidade e à sua identidade.

Diante do exposto, este estudo investiga, como problema de pesquisa, se a identidade cultural de São Paulo está em pleno processo de transformação, incluindo o entretenimento como mais um elemento de sua identidade cultural compondo sua narrativa identitária.

Identidade cultural historicamente centrada na imagem de cidade cosmopolita, com ênfase em seu poder industrial, caracterizada pela velocidade, pelo trabalho e pelo progresso (SALIBA, 2004). Indícios dessa identidade não faltam. São Paulo foi, devido a seu parque industrial, definida por seus cronistas como a "Locomotiva do Brasil", a "Chicago da América Latina", a "cidade não desperta, apenas acerta sua posição", , do paulistano que só sabe trabalhar, da cidade que nunca dorme.

Nas últimas décadas, a identidade da cidade industrial, da velocidade, do trabalho e do progresso vem sendo alterada, agregando mais um elemento à sua identidade cultural, relacionado ao entretenimento, que agora compõe sua narrativa identitária. Seus cronistas contemporâneos ambientam suas histórias nos espaços de entretenimento e contam a vida de seus frequentadores. O cinema, o teatro, as novelas, as músicas, baseiam seus enredos e letras nos acontecimentos dos bares, restaurantes, casas noturnas, e respectivos personagens em seus habitués.

Jornais, revistas, emissoras de rádio e televisão possuem seções especializadas e jornalistas exclusivos para a cobertura das opções de entretenimento em São Paulo. Sites de internet sobre o entretenimento da cidade são impossíveis de ser contabilizados. Aplicativos para smartphones (apps) descrevem, classificam e localizam restaurantes,

\footnotetext{
${ }^{3}$ Sinfonia Paulistana, retrato de uma cidade de Billy Blanco (1974). Música utilizada como vinheta de programa matinal da Rádio Panamericana.
} 
teatros, cinemas e casas noturnas na cidade. E até mesmo as empresas públicas e privadas de promoção turística, como a São Paulo Turismo e a São Paulo Convention \& Visitors Bureau, destacam a variedade de possibilidades de entretenimento em São Paulo.

Essa nova forma de narrar a cidade demonstra uma mudança não apenas no perfil de sua economia, mas é forte indício para fundamentar a hipótese de ser o entretenimento um componente dos hábitos e costumes de seus habitantes, a ponto de agregar mais um elemento à identidade cultural da cidade e à sua narrativa identitária, que, no tempo presente, é descrita como, além da cidade da indústria, da velocidade, do trabalho e do progresso, a cidade do entretenimento.

\section{Método}

O presente estudo é qualitativo, classificado como exploratório, por proporcionar maior familiaridade com os problemas de pesquisa, e descritivo, por ter como objetivo a descrição de características do fenômeno a ser compreendido (VEAL, 2011), utilizou, ainda, a abordagem da indução, pois o estudo envolve busca e explicação da relação do entretenimento com a cidade de São Paulo.

Com o objetivo de estudar as relação entre entretenimento e a identidade cultural da cidade de São Paulo foi realizadas uma pesquisa bibliográfica, útil para a definição de conceitos, como entretenimento e identidade cultural, contribuindo, ainda, para a compreensão de um processo em pleno curso e para a reconstituição de uma situação passada.

Para captar se o entretenimento tornou-se mais um componente da identidade cultural de São Paulo, foram analisadas as narrativas identitárias produzidas sobre a cidade, para Hall (2006) são indícios que revelam nosso pertencimento a culturas 
étnicas, raciais, linguísticas, religiosas, regionais e nacionais, fornecendo imagens que simbolizam e representam nossa identidade.

Assim, para comprovar a identidade cultural tradicional da cidade, como industrial, vinculada a velocidade, ao trabalho e ao progresso, foram consideradas e analisadas como narrativas identitárias, (a) o processo de construção da narrativa histórica paulista nobiliárquica e bandeirista e (b) as músicas Sinfonia Paulistana, Trem das Onze e Sampa, que estão incorporadas ao imaginário paulistano. Para evidenciar a relevância do entretenimento em São Paulo foram analisados, (a) dados da economia da cidade relacionados ao setor do entretenimento, (b) inclusive em sua dimensão de empreendimento econômico, (c) indícios de como o entretenimento tornou-se conteúdo obrigatório nos meios de comunicação paulistanos, como jornais, revistas, emissoras de rádio e televisão e (d) o entretenimento como atrativo turístico da cidade de São Paulo, por meio das políticas de promoção turística da São Paulo Turismo - Spturis.

Por fim, para sustentar que, no tempo presente, o entretenimento foi incorporado à identidade cultural paulistana, foram escolhidas narrativas identitárias, que descrevem, mas também imaginam a cidade (CANCLINI, 2010) em diferentes cenários, épocas, além de relatar as mudanças de hábitos, costumes e suas singularidades. A partir desses critérios analisou-se, (a) o seriado "Alice” produzido pela Home Box Office (HBO), (b) as músicas "Saudosa Maloca", "Iracema”, "Conselho de Mulher”, "Nóis Viemos Aqui Pra Quê" e "No Morro da Casa Verde" interpretadas por Adoniram Barbosa e o livro "Noites Urbanas" de Daniel Piza.

\section{Breves considerações sobre o entretenimento}

O termo entretenimento, seu entendimento e significado contemporâneo, está vinculado ao empresariado norte-americano, referindo-se a atividades programadas 
quase sempre pagas, com o objetivo de simples diversão, distração, recreação (TRIGO, 2008, p.25), reunidas em um mesmo fenômeno, porém com características muito diferentes entre si, articuladas como mercadorias, com a finalidade de consumo especificamente caracterizado pelo prazer.

Esse grande e difuso grupo, que pode ser denominado entretenimento, possibilita transformar infinitas atividades em mercadoria para consumo, ou, como afirma Debord (2008), em espetáculo, desde as mais corriqueiras, populares e baratas às mais exclusivas, sofisticadas e caras.

Diferentes sociedades, ao longo de seu processo histórico de formação, parecem sempre ter algum tipo de atividade divertida e programada em seus calendários religiosos e não religiosos, como brincadeiras de rua, jogos, festas, circos, teatros, shows, feiras, campeonatos, romarias, procissões e quermesses (TRIGO, 2008, p.26). Mas foi apenas no século XX que o entretenimento adquiriu a característica de consumo em massa, por meio do cinema, rádio, televisão e, mais recentemente, com os computadores que, conectados entre si, formam a world wide web, reforçando a relação entre consumo de massa e entretenimento.

Ao apresentar suas considerações sobre entretenimento nesse período histórico, Gabler enfatiza:

[...] Eram gratificações e não edificações, transigência e não transcendência, reação e não contemplação, escape em vez de submissão às instruções morais. Como disse um elitista, a diferença entre entretenimento e arte é a diferença entre a "gratificação espúria e a experiência genuína como degrau para uma maior realização pessoal". [...] Um dos dogmas da cultura era que a arte exigia esforço para ser apreciada, sobretudo esforço intelectual, mas o entretenimento não fazia nenhuma exigência a seu público [...] trabalhava apenas a serviço dos sentidos e das emoções; era a reação passiva recompensada pela diversão. Operando sobre as emoções e sobre as vísceras, sobre os centros da irracionalidade e da irresponsabilidade, o entretenimento provocava reações excitando o sistema nervoso, quase da mesma forma que as drogas. De fato, era o entretenimento, e não a religião, como queria Marx, o ópio do povo (GABLER, 1999, p. 23-24). 
É possível conjecturar que a postura preconceituosa de parte da intelectualidade diante da cultura de massa tenha fundamentos no argumento de Gabler aqui reproduzido. A aristocracia reacionária nunca aceitou que as camadas populares se divertissem fora do alcance da Corte, da Igreja e do Estado. Apenas as festas de exceção, como o carnaval, feiras populares e quermesses organizadas pela igreja eram toleradas.

Ao se tornarem atividades independentes, lucrativas e orientadas pelos desejos do público, constituíram uma ameaça de perda, por parte das elites, de seu histórico poder para outras elites que estavam em pleno processo de formação, sem vínculos com o capitalismo industrial ou financeiro, mas com setores da atividade econômica, como a cultura de massa e o entretenimento.

$\mathrm{Na}$ origem latina da palavra entretenimento, estão inter, ou entre, e tenere, ou ter. Em sua evolução na língua inglesa, entertainment tem o sentido de "aquilo que diverte com distração ou recreação" e "um espetáculo público ou mostra destinada a interessar e divertir" (GABLER, 1999, p. 25), ou seja, os significados no latim ou no inglês estão atrelados à ideia de "ter entre". Enquanto a arte proporciona o ékstasis, do grego "deixar que saiamos de nós mesmos", proporcionando ao espectador a possibilidade de uma perspectiva fora dele, o entretenimento, ao contrário, induz o espectador para dentro dele e para dentro do próprio espectador, como uma negação à perspectiva. Portanto, "segundo os elitistas, enquanto a arte trata cada espectador, ouvinte ou leitor, como indivíduo, provocando uma reposta individual à obra, o entretenimento trata suas plateias como massa" (TRIGO, 2008, p. 32).

Não se pode ignorar a importância social, cultural e econômica do entretenimento na vida das pessoas. São inúmeros os indícios que apontam como ele permeia a vida social, tornando-se uma força econômica, referência cultural e estilo em 
vários grupos sociais, devendo ser encarado como mais uma das diversas característica definidoras das sociedades atuais e, como tal, um tema, apesar de recente, com potencial de ampliar a compreensão a respeito delas.

\section{A matéria-prima da identidade}

Há um consenso, segundo Castells, que, do ponto de vista sociológico, a identidade é sempre construída de uma matéria-prima muito variada, com múltiplos fornecedores, como a história, a geografia, a biologia, as instituições produtivas e reprodutivas, pela memória coletiva e por fantasias pessoais, pelos aparatos de poder e revelações de cunho religioso $(1999$, p. 23). Contudo, toda essa matéria-prima é intermediada por indivíduos, grupos sociais e sociedades que elaboram seu significado de acordo com tendências sociais e projetos econômicos, políticos e culturais presentes em sua estrutura social e sua visão de tempo-espaço. Canclini, a respeito desse assunto, escreveu: “A história dos movimentos identitários revela uma série de operações de seleção de elementos de diferentes épocas articulados pelos grupos hegemônicos em um relato que lhes dá coerência, dramaticidade e eloquência” (2008, p. XXIII).

Em São Paulo, o projeto de liderança econômica e política, somou-se ao cultural. Desde fins do século XIX, teatros, grandes salas de cinemas, instituições culturais, como escolas e liceus de arte, universidades, museus, inúmeros movimentos e manifestações culturais (como a semana de arte de 22 e, mais recentemente, a Virada Cultural), a efervescente vida noturna em bairros boêmios habitados por intelectuais e artistas, colocaram a cidade na vanguarda da produção e difusão da cultura no Brasil. A São Paulo moderna, do progresso tecnológico e econômico, projetou sua identidade de cidade cosmopolita, como Nova Iorque ou Paris, por meio da cultura e do 
entretenimento, que assumiram papel significativo como conteúdo simbólico de sua identidade.

Para Castells (1999), quem constrói e para quê essa identidade é construída são, em grande medida, os determinantes do conteúdo simbólico da identidade, assim como de seu significado para os que se identificam com ela ou dela se excluem.

O processo de construção da identidade de São Paulo revela, como aponta Castells, relações de poder próprias da identidade legitimadora. A elite paulistana, ao demandar, criar e fruir a cultura e o entretenimento, legitimou sua posição dominante. Mas, ao mesmo tempo, a resistência aos padrões culturais e de comportamento, vigentes à época, assumidos por essa elite, gerou movimentos de oposição no sentido da identidade de resistência, que também contribuíram para a identidade da cidade e seus habitantes.

O surgimento de novos atores sociais, construindo sua identidade, no sentido de uma identidade de projeto, e redefinido sua posição na sociedade a partir do entretenimento, está em pleno processo no tempo presente em São Paulo. Uma elite não sustentada pelo poder econômico tradicional, mas pela renda obtida por meio dos negócios ligados ao setor do entretenimento, começa a buscar espaço político, ocupando cargos legislativos e executivos e, assim, influenciando os rumos da cidade.

Enquanto Castells (1999) enfatiza as relações de poder, Hall (2006, p. 10) centra sua definição de identidade no elemento tempo. Ao invés da identidade plenamente unificada, a multiplicidade dos sistemas de significação e representação cultural nos confronta como "uma multiplicidade desconcertante e cambiante de identidades possíveis, com cada uma das quais poderíamos nos identificar - ao menos temporariamente" (2006, p. 13). Limena (2009, p. 64) afirma que numa análise não 
determinista, a identidade não pode mais ser presumida a partir de regras ou de objetivações estáveis e sim entendida como uma obra em construção.

Sem adotar ou mesmo discutir os conceitos de pós-moderno e sujeito pósmoderno, apresentados por Hall, o que o autor denomina de diferentes momentos, esta pesquisa considera como processos de longa duração, que se iniciam e se consolidam em momentos e ritmos diferentes, não coincidentes, que, no tempo não de uma, mas de várias gerações, são sobrepostas, o que segundo Limena (2009, p. 74) possibilita assumir uma concepção processual, dinâmica e aberta de identidade: a São Paulo da indústria, da velocidade, do trabalho, do progresso, centro financeiro e comercial, ainda é parte importante da identidade da cidade, mas o setor de entretenimento, em um longo processo iniciado na virada do século XIX para o século XX, está sendo incorporado à multiplicidade de fatores identitários culturais da cidade, tornando-se parte de sua narrativa.

\section{As construção da identidade da cidade e suas narrativas históricas: a velocidade, o trabalho e o progresso}

Vam'bora, vam'bora/Olha a hora, vam'bora/Vam'bora, vam'bora/Olha a hora, vam'bora/Vam'bora, vam'bora!/São Paulo que amanhece trabalhando/São Paulo que não sabe adormecer/Porque durante a noite/Paulista vai pensando nas coisas que de dia vai fazer/São Paulo todo frio quando amanhecer/Correndo no seu tanto que fazer/Na reza do paulista/Trabalho é o padre nosso/É a prece/De quem luta e quer vencer

$\mathrm{Na}$ canção de Billy Blanco ${ }^{4}$, que por décadas desperta a cidade, e retira do repouso de forma nada sutil seus habitantes, três elementos estão presentes. Como em uma máquina, composta por engrenagens, o trabalho, que na "reza do paulista" é o

\footnotetext{
${ }^{4}$ Sinfonia Paulistana, retrato de uma cidade de Billy Blanco (1974). Música utilizada como vinheta de programa matinal da Rádio Panamericana.
} 
Padre Nosso, produz mobilidade, induzindo à velocidade, que reflete o ritmo do progresso da cidade locomotiva. Velocidade, trabalho e progresso formaram o triádico da identidade de São Paulo (SALIBA, 2004).

Sempre ligeiro na rua/Como quem sabe o que quer/Vai o paulista na sua/Para o que der e vier/A cidade não desperta/Apenas acerta/A sua posição/Porque tudo se repete/São sete, e às sete/Explode em multidão/Portas de aço levantam/Todos parecem correr/Não correm "de” correm "para”/Para São Paulo crescer

A versão radiofônica da música, mais acelerada que a gravação original, uma "valsa a galope", como definiu seu autor, reforça a sensação de urgência e velocidade. A cidade e sua população sempre ligeira na rua sabem o que querem, correm com pressa e às sete explodem em multidão.

Em pesquisa, a Folha de São Paulo (TOLEDO, p. 13-6, 2003) escolheu duas músicas-símbolo da cidade: Trem das onze, de Adoniran Barbosa, gravada em 1964, enfatizando um veículo de transporte rápido das massas, e Sampa, de Caetano Veloso, gravada em 1978, narrando o efeito catártico de um importante cruzamento de avenidas. Essas músicas enfatizam, assim como a Sinfonia Paulistana, o movimento, o trânsito, a velocidade, o progresso, a impermanência. Apesar de simples as três músicas, exemplificam o que Saliba (2004, p. 558) define como a identidade cultural de uma cidade, composta "de uma formidável tessitura de detalhes, que de tão excessivamente visíveis, tornaram-se indícios de uma sintaxe silenciosa da vida social."

Rimando com a paisagem inóspita das cidades, metrópoles pouco amistosas, resultantes da modernidade, de crescimento não ordenado, na história da capital paulista tornou-se um de seus elementos identitários a mobilidade, o momento pelo momento, a velocidade própria do progresso, colocada em movimento contínuo pelo trabalho da 
cidade e, como é descrito na valsa a galope, o paulistano "não sabe adormecer" e, por consequência não sonha, é incapaz de romper com o imediato, não vislumbra nada além do imediato, pensa apenas no que realizará no dia seguinte: Porque durante a noite/Paulista vai pensando/Nas coisas que de dia vai fazer.

Essa narrativa histórica de São Paulo, fundada no estereótipo trabalho que gera o movimento na direção do progresso, penetrou de tal maneira no fluxo da existência dos paulistanos que o binômio velocidade-trabalho parece ter perdido suas asperezas e contradições, possuindo seus fins em si próprio, numa circularidade auto explicativa, sem nada que a transcenda. O “correr para São Paulo crescer”, entre tantos movimentos indicados na canção, por pouco não se tornou parte da própria natureza da cidade e das relações do dia a dia com sua paisagem, com sua complexa geografia e, até mesmo, com as imagens associadas a sua identidade, a ponto de "tudo nos parecer tão repetitivo, tão rotineiro e tão familiar que quase esquecemos que a identidade de São Paulo foi criada, construída, inventada" (SALIBA, 2004, p. 558).

A identidade de São Paulo está muito mais ancorada nas imagens criadas a respeito dela do que verdadeiramente no que ela é: múltipla, fragmentada e, portanto, pouco reconhecível e apreensível. A narrativa histórica associou seus acontecimentos mais significativos à velocidade, mobilidade, trabalho e progresso, palavras acessíveis e de simples compreensão, de grande impacto, quase como um slogan publicitário, que criam na "terra da garoa" uma bruma, uma neblina que envolve a memória do paulistano, induzindo-o a tomar essas palavras como elementos essenciais da identidade de São Paulo.

A narrativa histórica da cidade parece ter vencido as forças desagregadoras da memória, superou, corrigiu, aplainou outras palavras que também e tão bem poderiam 
ter definido sua identidade. "São Paulo não pode parar", "a Chicago da América Latina", "São Paulo, a cidade que mais cresce no mundo", frases do senso comum, porém, significativas de seus estereótipos, refrãos de uma música que tenta compor a identidade cultural da cidade e que são indícios do longo processo de construção de sua narrativa histórica. Por ser construção, não é incorreto afirmar que São Paulo não tem uma identidade, mas múltiplas, variadas identidades, que são como camadas, como estratos que vão se empilhando, sem nunca serem cristalizados. A canção que acorda os paulistanos é apenas um indício, um artefato que está na camada acima de outras mais profundas, relevadas pelas narrativas identitárias da cidade de São Paulo.

\subsection{A "segunda fundação" e a formação da identidade da cidade de São Paulo}

Foi a partir da denominada "segunda fundação" de São Paulo, periodizada por Love (1982) entre 1870, momento da gênese do acelerado processo de metropolização da cidade, e 1929, com a quebra da bolsa de valores de Nova Iorque e a consequente crise da economia cafeeira ou, com uma periodização mais estendida, com o início da industrialização da cidade na década de 1950, quando começou a ser formada a narrativa da identidade da cidade. Vale destacar que a própria expressão "segunda fundação" é muito significativa, pois sugere que a vertiginosa metropolização da cidade foi impactante sobre sua história até aquele momento, sobre seu passado anterior, sobre sua memória, consequentemente, sobre a sua identidade.

Esse é o momento da gênese das frases, incessantemente reproduzidas para definir São Paulo como "a cidade que mais cresce no mundo", "que não pode parar", "que nunca dorme". Elas são indícios dos efeitos da devastadora metropolização que

ofuscou as lembranças pessoais e a memória coletiva. Tal esquecimento não é exclusivo de São Paulo, mas comum no processo histórico de criação de muitas grandes cidades 
que precisaram produzir uma unanimidade baseada no triunfo do moderno sobre o seu passado colonial. Contudo, na cidade de São Paulo, esse processo de metropolização foi mais intenso que em outros lugares, nela destruiu-se não somente toda e qualquer referência material, mas todo e qualquer resquício de referência simbólica estável.

A São Paulo megalópole nasceu, em sua "segunda fundação", como uma incógnita, lapidando suas arestas, apagando seu passado, ou retirando dele só o que interessava para reforçar a tese do progresso em si mesmo. Sevcenko (1989, p. 151), ao comparar as cidades do Rio de Janeiro e São Paulo, afirma que os signos de identificação desta última não eram estáveis, mas sim processos em curso vertiginoso: fusão, especulação, crescimento, aceleração. Enfim, tudo aquilo que acentuou o triádico velocidade, trabalho, progresso.

Saliba (2004) argumenta que esse processo de esquecimento produziu algo como um vazio de tempo social, lentamente preenchido pela cultura, mais especificamente, pela invenção de um passado para a cidade que, na virada do século XIX para o XX e em sua décadas iniciais, passava por uma forte ruptura e desenraizamento temporal. O autor lembra que o poder de articular uma narrativa histórica "fornece a base substantiva para o surgimento da própria história paulista, fundada primeiro na fundação de nobiliarquias e, depois, pela própria criação de um passado bandeirista" (2004, p. 570).

Em São Paulo, as grandes linhas narrativas de uma história paulista, nobiliárquica e bandeirista, foram criadas após a Primeira Guerra. Saliba as define como uma narrativa monumental, assentada nas narrativas menores e fragmentadas, sobrepondo-as, saltando por sobre o passado mais recente, feio, conflitivo, anárquico, de uma cidade em que aos problemas da escravidão somaram-se os estigmas de uma 
imigração apressada e tumultuada, com o objetivo de conectar o fio da continuidade com um passado distante no tempo, criando uma aura quase mítica. Ao preencher o vazio de tempo social, ofuscando as lembranças, a grande narrativa reforça o processo de esquecimento social.

A construção da identidade de São Paulo fundamentou-se no ofuscamento da memória, tornando-a suficientemente opaca, ressaltando as imagens consensuais. A bandeirante foi a mais conhecida dessas imagens. O vocábulo paulista foi associado ao sentimento de bandeirante, definido por Queiroz (1998, p. 83) como

\footnotetext{
“[...] por feitos do passado, quando conquistou, para a Coroa portuguesa, o imenso interior brasileiro, caracterizando-se pela audácia, pelo desejo imoderado de conquista, pelo sentimento de independência, pela vocação de mando, pela lealdade".
}

Essa é uma narrativa mitológica que foi construída, propositalmente elaborada, inventada durante os anos da metropolização da cidade. Em 1813, O Diccionario de Lingua Portugueza de Moraes e Silva, editado em Lisboa, definia, sem sua aura heroica, bandeira como "associações de homens que vão pelos sertões debaixo de uma cabeça, descobrir terras mineiras. Dantes chamavam assim os que ião descobrir índios gentios e conduzi-los, ou cativá-los ou resgatá-los.” O significado do substantivo bandeirante, em 1913, durante o processo de metropolização, aparece no Novo Dicionário da Língua Portuguesa como o "individuo que no Brasil faz parte dos bandos, destinados a explorar os sertões, atacar selvagens etc." Contudo, em 1938, no dicionário de Laurentino Freire, aparece ao lado do substantivo bandeirante o adjetivo "Bandeirante: o natural de São Paulo.” Para Saliba (2004, p. 572), esse foi o momento em que a narrativa histórica consolidou seu sentido, aplainado as rebarbas de significado do passado, forjando o auto reconhecimento social, criando uma síntese para a identidade de São Paulo. 
O modernismo paulistano, ocorrido também durante o processo de metropolização, que nasceu como movimento cultural a reboque da busca da hegemonia pelas elites paulistas, contribuiu para o ofuscamento da memória. O símbolo desse movimento, a Semana de Arte Moderna, ocorreu em uma conjuntura denominada nacionalismo paulista, marcada por várias celebrações, como a inauguração, em 1911, do Theatro Municipal, a urbanização do Vale do Anhangabaú e dos pântanos do Carmo, que deu lugar ao Parque D. Pedro, denominado pela imprensa como a versão paulista do Hide Park londrino (SEVCENKO, 1992, p. 138-142), a reorganização, em 1914, do Museu Paulista, hegemonicamente dedicado à história de São Paulo, e a criação, em 1918, do nada sutil brasão metropolitano: non ducor duco (não sou conduzido, conduzo) (PINTO, 2002, p. 48-51).

Mesmo considerando que em termos estéticos o modernismo não pode ser resumido apenas pela Semana de 1922, é sintomática sua opção pela renovação estética vinculada às vanguardas europeias. Ela revela uma estratégia paulista que, como já destacado, visava sobrepor o passado recente, o passado pré metropolização, em que a tradição estética teve como referência o naturalismo, o simbolismo, o parnasianismo, controlada em escala nacional pelo Rio de Janeiro (MORAES, 1986).

\subsection{Identidade cultural da cidade de São Paulo e suas narrativas}

Com a "segunda fundação" de São Paulo a identidade cultural da cidade e suas narrativas adquirem seus elementos mais marcantes: cidade industrial, velocidade, trabalho e progresso. Para Hall (2006, p. 50), as narrativas são representações, o sentido que influencia e organiza tanto nossas ações quanto a concepção que temos de nós mesmos. Elas produzem sentidos com os quais podemos nos identificar e construir a 
identidade. As narrativas da cidade contêm as memórias que cumprem a importante função de interligar presente e passado às imagens construídas da cidade.

A história, a música, a literatura, os meios de comunicação e o cinema compõem as narrativas da cidade, fornecendo as imagens que simbolizam e representam as experiências que dão sentido à sua identidade. As narrativas projetam as fantasias dos que vivem na cidade e constituem-se em documentos que espelham seu imaginário. Nelas estão contidas as situações e a sequência de acontecimentos que revelam as transformações, os conflitos, as emoções, os tumultos, as agitações e os dramas que permitem, de maneira complexa, completa e profunda, descrever, explicar e interpretar, o que está ocorrendo com a identidade cultural da cidade.

Para Canclini (2010, p. 90), buscar o sentido da cidade passa por "explorar a estrutura e desestruturação de formas demográficas, socioeconômicas e culturais que têm uma certa 'realidade' objetável”, contudo é fundamental "indagar como os sujeitos representam para si mesmos os atos com os quais habitam essas estruturas." O autor afirma que a proliferação de discursos dos diferentes grupos de habitantes da metrópole projeta suas fantasias, portanto, são documentos do imaginário, registram os dramas da cidade e ajudam a explicar e interpretar o que está ocorrendo.

Daí o interesse em trabalhar com textos que descrevem mas também imaginam a metrópole: os relatos de informantes, as crônicas de jornais e literárias, as fotos, o que dizem o rádio, a televisão e a música que narram nossos passos urbanos (2010, p. 90).

Vários são os textos que descrevem e imaginam, portanto, narram a cidade. Nos programas de televisão e rádio, nas músicas, nos jornais e revistas, no cinema, na literatura, utilizados no presente estudo, estão impressos os elementos que compõem a identidade. Sua análise revela que a identidade de São Paulo está em transformação, 
acrescendo o entretenimento como mais um elemento cultural identitário, que fornece cenários, personagens, imagens, histórias, dramas e inspiração, à narrativa da cidade da indústria, da velocidade, do trabalho e do progresso, e no tempo presente, também, a cidade do entretenimento.

\section{A relevância do entretenimento para a cidade de São Paulo}

O setor de entretenimento, como já afirmado, em São Paulo tornou-se um de seus elementos culturais identitários, compondo sua narrativa identitária, refletindo em diferentes dimensões da vida da capital paulista, entre elas, destacam-se as seguintes:

\subsection{Relevância do entretenimento para a economia da cidade}

O mercado consumidor de entretenimento também é revelador da importância do setor para a cidade. Paulistanos, moradores da região metropolitana e do interior do Estado, frequentadores assíduos ou eventuais da cidade injetam milhões de reais na economia, constituindo de fato um mercado consumidor (D'ALESSIO, 2008).

De acordo com pesquisa realizada pelo Datafolha e Revista São Paulo que entrevistou 807 pessoas, entre os dias $1^{\circ}$ e $4^{\circ}$ de março de 2012, sobre seus hábitos de lazer, relacionados apenas à fruição do entretenimento noturno na cidade, o gasto médio de uma pessoa na noite paulistana é de $\mathrm{R} \$ 109,70$, sendo que $28 \%$ gastam até $\mathrm{R} \$ 50,00$, $42 \%$ entre $\mathrm{R} \$ 50,00$ e $\mathrm{R} \$ 100,00,16 \%$ entre $\mathrm{R} \$ 100,00$ e $\mathrm{R} \$ 150,00$ e $14 \%$ chegam a gastar mais de $\mathrm{R} \$ 150,00$, índice que sobe para $42 \%$, entre os que saem todas as noites, e para $27 \%$ entre os casados. Um exemplo citado na pesquisa é do nutricionista Lucas Ferraz, de 24 anos, que sai três vezes por semana

\footnotetext{
As rondas de Lucas consomem até $30 \%$ de seu salário - ele já chegou a gastar R\$1.000,00 em uma única noite com a namorada. "Em São Paulo, tem muita coisa para fazer a noite. Você pode sair todos os dias da semana e não repetir o programa" (RODRIGUES, 2012, p.35).
} 
Pessoas como Lucas não são incomuns em São Paulo. Segundo a mesma pesquisa, o faturamento de restaurantes, bares e casas noturnas cresceu $15 \%$ entre os anos de 2009 e 2010. Segundo a Associação Brasileira de Bares e Restaurantes (Abrasel), o montante passou de $\mathrm{R} \$ 37,5$ milhões para $\mathrm{R} \$ 46$ milhões.

Os números relacionados à economia do entretenimento reforçam seu significado para a cidade de São Paulo. Desenvolveu-se uma indústria que emprega diretamente em suas atividades milhares de pessoas, outras tantas em suas atividades satélites, como logística, treinamento e formação de mão-de-obra, moda, construção civil, decoração, comunicação e outras tantas, estendendo a cadeia econômica para muito além das atividades de entretenimento (MIRANDA, 2002, p.33). Somente o setor de restaurantes, segundo a Abrasel, emprega cerca de 780 mil pessoas, o que faz deste um dos maiores geradores de empregos da cidade.

\subsection{Relevância do entretenimento a partir dos meios de comunicação}

Respondendo ao crescimento que os números acima demonstram, os meios de comunicação dedicam considerável espaço e tempo ao entretenimento. Os jornais de grande circulação, como Folha de São Paulo e O Estado de São Paulo, possuem cadernos especializados no tema. A Folha de São Paulo, além de seu caderno Folha Ilustrada, com frequência diária, encarta às sextas-feiras O Guia Folha e, aos domingos, a Revista São Paulo, com informações sobre as possibilidades de entretenimento da capital paulista. Revistas semanais de circulação nacional, como Veja e Época, possuem encartes em forma de revista, denominadas, respectivamente, Veja São Paulo e Época São Paulo, que também tratam das opções de entretenimento na cidade.

A gastronomia em São Paulo pode ser considerada entretenimento, prova disto é o fato de a Veja São Paulo lançar anualmente, no mês setembro, uma edição especial 
dedicada à gastronomia da cidade, chamada "Comer e Beber", dividida em seções com comidinhas, bares, restaurantes e vinhos. Em 1997, ano de sua primeira edição, a revista foi lançada com 172 páginas, apresentando 350 restaurantes e 100 bares. Em sua última edição (2013/2014), foram 548 páginas, que apresentam detalhadamente 1268 endereços, de pastel de feira aos requintados restaurantes de alta cozinha ${ }^{5}$.

Tais números dão a medida da importância da gastronomia como entretenimento na cidade. São também indícios do que é hoje conteúdo presente e obrigatório em todos os jornais e revistas de grande circulação, independente de sua especialização ou segmentação. Em São Paulo, as opções de entretenimento tornaram-se informações indispensáveis, demonstrando como sua fruição está incorporada aos hábitos e costumes do paulistano.

As emissoras de rádio e televisão não fogem à regra. Rádios com programação dedicada à música ou exclusivamente a notícias possuem boletins diários sobre entretenimento. Dois exemplos são as rádios Central Brasileira de Notícias $(\mathrm{CBN})$ e Bandeirantes News (Band News), que possuem colunistas especializados no tema e boletins segmentados em gastronomia, cinema, teatro, restaurantes, casas noturnas e espetáculos, que procuram manter os ouvintes informados sobre as possibilidades de entretenimento da cidade.

Já a internet é espaço de incontáveis web sites, blogs e vlogs (vídeo blogs) sobre o tema. Os meios de comunicação já citados possuem em suas versões online páginas dedicadas ao entretenimento. Um web site paulistano com conteúdo totalmente dedicado ao tema é o "Uia Diário". Tal site merece destaque não apenas por ser pioneiro (no ar há desde 2008), mas por ser um guia online de entretenimento que tem

\footnotetext{
${ }^{5}$ Disponível em: $<$ http://vejabrasil.abril.com.br/portal/>. Acesso em: 19 fev. 2013.
} 
como diferencial um amplo serviço de informações sobre shows, exposições, teatro, cinema, restaurantes, festas e eventos culturais na capital paulista, diariamente.

Aplicativos para smartphones, os chamados apps, são outros bons indícios da importância do setor de entretenimento para a cidade. Possuindo funções tão diversificadas que é impossível elencá-las. Os apps com funções de entretenimento ou para sua promoção são muito populares, ocupando os primeiros lugares em downloads. O entretenimento em São Paulo é tema de 24 apps, que podem ser divididos em dois grupos.

No primeiro grupo, estão apps dedicados ao turismo na cidade de São Paulo, que destacam as opções. O segundo grupo é formado por apps que tratam especificamente de restaurantes, bares, cinemas, teatros e casas noturnas. Todos eles com seções específicas sobre cinema, teatro, restaurantes e vida noturna de São Paulo, além de funcionalidades, como sistema de busca e mapa de localização geográfica que traça rotas a partir da localização do usuário até o estabelecimento desejado, por ônibus, carro ou a pé. Em seu texto de apresentação, o app "São Paulo é tudo de bom", produzido pela São Paulo Convention \& Visitors Bureau, a cidade é descrita por suas possibilidades de experiências variadas de entretenimento, que vão da gastronomia à vida noturna.

Já o texto que descreve o app "SP Mobile", da Spturis, afirma ter como objetivo posicionar e promover a cidade de São Paulo como a capital dos negócios, conhecimento e entretenimento da América Latina, destacando seu caráter vanguardista e cultural. Entre suas funcionalidades estão seções, como "Comes e bebes", que indicam e descrevem bares, restaurantes e "Entretenimento" - baladas, cinemas e teatros. 
Para além dos expressivos números de apps que tratam do tema, é preciso destacar que alguns deles estão entre os mais baixados das lojas virtuais. O app "Veja Comer e Beber", que apesar do nome não trata apenas de bares e restaurantes, mas também de casas noturnas, é um dos aplicativos mais baixados no Brasil. Desde seu lançamento em abril de 2010, ao custo de US\$2.99, com, em média, 55 mil downloads por mês, figura na lista dos 25 apps mais baixados na Apple Store Brasil, ficando em primeiro lugar, por dias, todas as vezes que são lançadas atualizações ${ }^{6}$.

Tais dados são muito significativos, fornecem uma medida objetiva da importância dessas atividades nos hábitos e costumes dos paulistanos, demonstrando o tamanho da demanda pela fruição do entretenimento.

\subsection{Relevância do entretenimento como empreendimento econômico}

A análise dos empreendimentos de entretenimento, particularmente os relacionados à noite, fornece números que reforçam a relevância do entretenimento para a cidade de São Paulo.

Empresários investem somas significativas em entretenimento, obtendo retornos expressivos. Exemplos não faltam. O grupo Clash, constituído em 2008, iniciou suas atividades com a casa noturna Clash, na Barra Funda, com investimento de R\$ 1 milhão e faturamento de R\$ 3 milhões. O grupo nos últimos anos inaugurou três novas casas: o clube Lab, na região da rua Augusta, o restaurante espanhol Donostia, em Pinheiros, e uma lanchonete na rua Augusta. Os lucros do grupo, incluindo os serviços de catering e o aluguel dos espaços para a promoção de eventos especiais, somaram em 2011 cerca de R\$ 11 milhões (RODRIGUES, 2012, p.35).

\footnotetext{
${ }^{6}$ Veja Beber e Comer. Disponível em:

$<$ http://www.publiabril.com.br/upload/files/0000/0751/App_VEJA_Comer_e_Beber_mar12.pdf $>$. Acesso em: 03 mai. 2012.
} 
Outro grupo de 43 investidores criou a empresa A.Life Entertainment Group, especializada em casas noturnas luxuosas, que faturam $\mathrm{R} \$ 75$ milhões por ano, atendendo 70 mil pessoas por mês (LOMBARDI, 2012). Com números semelhantes, destaca-se a casa noturna Pink Elephant, com investimento de R $\$ 5$ milhões, funcionou por dois anos, e o faturamento mensal oscilou entre $\mathrm{R} \$ 300$ mil e $\mathrm{R} \$ 2$ milhões.

O setor de entretenimento paulistano tornou-se, como fica evidente nos exemplos anteriores, ótimo negócio. Originando empresários que fizeram carreira, empreendendo exclusivamente no entretenimento. Um exemplo é José Victor Oliva que, em 1979, com 23 anos, criou, além do Gallery, ícone da noite paulista por 28 anos, casas noturnas como o Banana Café, Moinho Santo Antônio e Resumo da Ópera, sendo conhecido como rei da noite. Hoje tal status pertence a Facundo Guerra, denominado por reportagem da Revista Veja São Paulo como "o novo reizinho da noite":

\begin{abstract}
Dentro da riquíssima galeria de personagens que fizeram e fazem sucesso agitando a noite paulistana, Facundo Guerra, um argentino nascido em Córdoba e radicado no Brasil desde 1976, já merece um capítulo exclusivo. Ele entrou no ramo por acaso, depois de perder o emprego de executivo que lhe rendia um salário mensal de 10.000 reais e de uma tentativa frustrada de se associar a uma marca de roupas. Mesmo sem experiência no mercado da boemia, topou o convite de um amigo para virar sócio de uma boate construída dentro de um galpão de 400 metros quadrados onde funcionava uma oficina de carros, na parte central da Rua Augusta, ao lado de inferninhos, hotéis de alta rotatividade e botecos vagabundos (GIOVANELLI, 2011).
\end{abstract}

Facundo Guerra, que emprega 90 funcionários diretos e 210 indiretos, fez outros investimentos que, somados, chegam a R\$ 1,4 milhão, como os bares Z Carniceria, na própria rua Augusta, e Volt, na rua Haddock Lobo; as casas noturnas Lions, na avenida Brigadeiro Luís Antônio e a Yatche, no Bixiga, além da casa de espetáculos Cine Joia, no bairro da Liberdade. Em julho de 2011, o público mensal de seus negócios chegava à metade das 60 mil pessoas que frequentam as principais casas noturna da cidade: Clash, D-Edge, Estúdio Emme, Disco e Kiss \& Fly. 
Assim como o Gallery de seu antecessor, a casa noturna Vegas, de Facundo Guerra, fez história, sendo inclusive apontada como desencadeadora da revitalização do degradado Baixo Augusta, tradicional região boêmia localizada entre a avenida Paulista, rua Augusta, praça Roosevelt e rua da Consolação. Região que hoje é um polo de entretenimento, somando, entre bares, restaurantes, cinemas, teatros e casas noturnas, cinquenta estabelecimentos.

Um efeito dessa revitalização é que, após 25 anos, a rua Augusta recebe o lançamento de dois condomínios residenciais, um deles com cerca de 200 apartamentos, com metro quadrado estimado, ainda no lançamento do empreendimento, em $\mathrm{R} \$ 15$ mil, valor próximo ao de bairros residenciais tradicionais como Moema e Pinheiros.

A região está sofrendo um processo de gentrificação ${ }^{7}$, como aconteceu com o Soho, em Nova Iorque, que recebeu, em um curto espaço de tempo, jovens artistas, valorizando o bairro até que não mais pudessem viver nele, pelo alto custo. Fenômeno que se repete na Vila Madalena. Nos anos 1970 e 1980, a região atraiu jovens devido à sua vida boêmia e cultural, fato que a valorizou, gerando o encarecimento dos aluguéis e a consequente mudança do perfil de seus moradores. O Baixo Augusta segue essa tendência, e em cinco anos, como prevê Facundo Guerra, a região ficará mais residencial, mais parecida com os Jardins.

\subsection{Relevância do entretenimento para a promoção turística da cidade}

Uma consequência do crescimento do setor de entretenimento em São Paulo foi a sua transformação em atrativo turístico. Hoje ele é parte obrigatória do roteiro de visitação dos que vão a São Paulo a negócio ou a lazer. Surge o turismo com motivação na fruição do entretenimento, um público cada vez maior, vindo das cidades do interior

\footnotetext{
${ }^{7}$ O neologismo gentrification foi criado em 1964 pela socióloga inglesa Ruth Glass, para definir a valorização imobiliária de bairros degradados de Londres, devido a intervenções governamentais e não governamentais, resultando em um enobrecimento urbano (BERNHARDT, s.d.).
} 
de São Paulo e de outros estados brasileiros, desejoso em conhecer o que suas cidades não oferecem.

Agências de turismo desenvolveram pacotes para esse público, conjugando hospedagem em hotéis de luxo, com todos os seus serviços, ingressos para peças de teatros, musicais, exposições, shows variados, reservas em restaurantes sofisticados e acesso privilegiado às casas noturnas mais concorridas. A Blumar Turismo e Viagens, por exemplo, sediada na cidade do Rio de Janeiro, oferece o pacote "Conheça São Paulo". No texto de apresentação do pacote, a cidade é redefinida não mais apenas como a cidade do trabalho, sua identificação tradicional, mas por seus atrativos de entretenimento:

\begin{abstract}
A Capital do Estado de São Paulo é o mais importante e dinâmico polo econômico da América Latina. São Paulo é uma cidade cosmopolita famosa por sua diversidade étnica e vida agitada. Mas, se engana quem pensa que em São Paulo só se vive para o trabalho. A cidade oferece excelentes opções de lazer e cultura para se aproveitar de dia ou à noite. São Paulo é uma cidade com diversas atrações que vão desde passeios culturais a compras. Outro ponto importante da cidade são os sofisticados restaurantes, São Paulo é reconhecido como um dos maiores e melhores polos gastronômicos do país. A vida noturna é bem agitada e com diversas opções para todos os gostos, diversos barzinhos, restaurantes e boates ${ }^{8}$.
\end{abstract}

A apresentação conta ainda com descrições específicas dos atrativos, que são divididos nos seguintes links: Arte e Cultura; Onde Comer; Natureza e Esportes; Vida Noturna; Compras e Atrações Turísticas. Nos textos dos atrativos Onde Comer e Vida Noturna, a cidade é definida como o melhor polo gastronômico do país, e os restaurantes são convertidos em atrações turísticas. A vida noturna aparece como agitada e diversificada, destacando a variedade de bares e casas noturnas.

\footnotetext{
${ }^{8}$ Disponível em: < http://www.blumar.com.br/cidades.cfm?cidade=sao\%20paulo $>$. Acesso em: 15 mai. 2012.
} 
Seguindo essa tendência, hotéis da cidade oferecem estadias diferenciadas aos finais de semana, quando a ocupação é menor. O Hotel Meliá e o InterContinental oferecem pacotes que incluem peças em cartaz nas proximidades. O Renaissance São Paulo Hotel disponibiliza em suas ofertas e promoções três que são fundamentadas nas possibilidades de fruição das opções de entretenimento da cidade $^{9}$. A primeira, denominada Stretch Your Weekend Package no Renaissance São Paulo Hotel, apresenta assim São Paulo: “A maior cidade da América Latina se torna muito mais viva aos finais de semana". A segunda oferta é o Taste of São Paulo, em que a gastronomia é a protagonista: "Sabores de todo o mundo, com a autenticidade de nossa cidade. Surpreenda-se!" A terceira, Renaissance On The Stage, em que o teatro é o destaque: "Entre em cena para conhecer o melhor de São Paulo. Aproveite o espetáculo!"

Tais ofertas e promoções criaram uma nova forma de paulistanos e paulistanas fruírem a cidade, transformando-se em turistas. Os moradores da capital já são 6,8\% do total de hóspedes, segundo levantamento feito no segundo semestre de 2011 pela Spturis. Há dois anos, esse número não ultrapassava 3\%.

Sensível ao fenômeno, a Folha de São Paulo investigou o assunto e, em reportagem publicada em 13 de janeiro de 2012, apresentou dados significativos, em que o entretenimento é um dos elementos desencadeadores da ocupação dos hotéis ${ }^{10}$. Citado pela reportagem, Toni Sando, diretor da São Paulo Convention \& Visitors Bureau, empresa que reúne vários segmentos do setor turístico, destaca as possibilidades de entretenimento da cidade: "O fim de semana em São Paulo tem programação intensa, boa gastronomia, espetáculos que vieram da Broadway". De

9 Disponível em: $<\underline{\mathrm{http}} / /$ hoteis.marriott.com.br/hotels/hotel-deals/saobr-renaissance-sao-paulohotel/index.asp >. Acesso em: 15 mai. 2012.

${ }^{10}$ Disponível em: $<$ http://www1.folha.uol.com.br/saopaulo/1032576-tarifas-menores-atraem-paulistanospara-hoteis-nos-fins-de-semana.shtml>. Acesso em: 15 mai. 2012. 
acordo com ele, a demanda acaba atraindo quem mora longe dos polos culturais e gastronômicos da cidade, concentrados nas zonas oeste e central, onde também estão localizados hotéis de alto padrão com esse tipo de pacote. "É gente que mora afastada do centro e quer se sentir turista sem pegar a estrada".

A Spturis, empresa de turismo e eventos de São Paulo, que tem como sócia majoritária a Prefeitura, visando promover a cidade como polo de turismo de negócios, tem utilizado o entretenimento para representar e apresentar a cidade. Um indício da importância do setor de entretenimento na promoção turística da cidade é a existência de uma diretoria exclusiva para o entretenimento, que destaca ser a cidade não apenas um destino de turismo de negócios, enfatizando sua oferta de cultura, gastronomia e entretenimento:

\begin{abstract}
A Diretoria de Turismo e Entretenimento atua na consolidação nacional e internacional da cidade como destino turístico. Para isso planeja e implanta projetos de estruturação da oferta turística, além de desenvolver ações de promoção, marketing e divulgação, com o objetivo de qualificar São Paulo como uma cidade cosmopolita, cultural, gastronômica e rica em entretenimento, o que a capacita para não apenas ser um grande destino de turismo de negócios ${ }^{11}$.
\end{abstract}

A diretoria ainda conta com uma gerência de promoção turística e entretenimento e uma coordenadoria de promoção de turismo de lazer e entretenimento. Para Luciane Leite, diretora de turismo e entretenimento da Spturis, entrevistada por Rodrigues (2012), visitantes a negócio e turistas aumentam as já longas filas das casas noturnas e restaurantes da cidade. Hoje, um dos fatores que motivam os visitantes a estenderem sua estadia em São Paulo é a oferta de entretenimento.

Tendência que vem sendo detectada há cinco anos, por pesquisa realizada pela Spturis sobre esse comportamento. Em 2011, 21\% dos visitantes e turistas optaram por

${ }^{11}$ Disponível em: $<$ http://www.spturis.com/v7/equipe-turismo.php $>$. Acesso em: 15 mai. 2012. 
ficar mais algum tempo na cidade para ir a casas noturnas e $17 \%$ para conhecer os restaurantes. De acordo com Luciane Leite,

[...] para nosso trabalho de promoção, os restaurantes e as casas noturnas são fundamentais. Aqui, há do eletrônico ao sertanejo, de botecos super tradicionais à restaurantes de reconhecimento internacional. É o grande diferencial da cidade (RODRIGUES, 2012, p.35).

Outro exemplo da relevância do entretenimento para turismo em São Paulo é a Virada Cultural. Inspirada na Nuit Blanche parisiense, tem como um de seus objetivos a promoção turística da cidade e sua conversão em metrópole internacional ${ }^{12}$. $\mathrm{O}$ evento promovido desde 2005 pela prefeitura da cidade de São Paulo, com 24 horas ininterruptas, conta com de eventos culturais dos mais variados tipos, como espetáculos musicais, peças de teatro, exposições de arte e história, entre outros. Durante a edição 2011 da Virada Cultural, foi realizada uma pesquisa para identificar o perfil socioeconômico do público presente e também obter uma avaliação geral da cidade e do megaevento.

Coordenada pela equipe do Observatório de Turismo da Spturis, a pesquisa aplicou 2.042 questionários e mostrou que 9,7\% do público são pessoas de fora da cidade, sendo 99,4\% desses visitantes de outros estados brasileiros, principalmente do Rio de Janeiro, Santa Catarina, Minas Gerais e Bahia, e também do interior do estado de São Paulo (cidades como Campinas, Limeira, Jundiaí, Sorocaba e Bragança Paulista), que permanecem na cidade por cerca de três dias e gastam, em média, $\mathrm{R} \$ 1.088,00$.

O mesmo pode-se dizer do programa "Fique Mais Um Dia", da Spturis, que incentiva os turistas de negócio a estender sua estadia na cidade. $\mathrm{O}$ site do programa e

12 Disponível em: $<$ http://spturis.com/v7/noticia.php?id=169>. Acesso em: 31 mai. 2012. 
seu caderno de divulgação enfatizam as possibilidades de entretenimento na cidade. $\mathrm{Na}$ capa do caderno, aparecem as frases: "São Paulo Fique mais um dia; Onde ficar, comer e se divertir: viva tudo o que a cidade tem de melhor; Passeios, Compras, Cultura, Lazer ao ar livre, Baladas, Programas para as crianças".

Em texto com que o ex-prefeito Gilberto Kassab apresenta o programa, a cidade é descrita como um grande centro de entretenimento, a exemplo Nova Iorque e Londres, com toda as facilidades das capitais europeias, com os melhores restaurantes, hotéis, cinemas e museus. Por fim, o prefeito convida: "ao chegar à cidade para fechar um negócio, fazer uma reunião ou participar de um evento, fique ao menos mais um dia e desfrute de todo esse universo de lazer. São Paulo está a sua disposição: aproveite.”

No web site YouTube, a Spturis possuiu um canal que compila os vídeos de diferentes origens, como programas de televisão, reportagens jornalísticas e vídeos institucionais próprios, abordando temas relacionados ao turismo na cidade. A análise desses vídeos revela a importância do setor de entretenimento, com sua gastronomia, espetáculos teatrais, shows, exposições e casas noturnas, para a promoção da cidade. Dos 157 vídeos postados no canal, quase a totalidade faz referência ao entretenimento. Mais especificamente, os vídeos institucionais, aqueles produzidos sob encomenda e orientação da Spturis, utilizam as possibilidades de entretenimento como meio de promoção turística. Tais vídeos são indícios que reforçam a importância do entretenimento como mais um elemento da identidade cultural de São Paulo.

Um exemplo são os vídeos da campanha Unimaginable, criada em 2010 pela agência Lew'Lara\TBWA para Spturis ${ }^{13}$. Personalidades paulistas, conhecidas dentro e fora do país, mostram seus talentos, tendo a cidade de São Paulo como inspiração: Alex

\footnotetext{
${ }^{13}$ Disponível em: $<$ http://ccsp.com.br/ultimas/noticia.php?id=49855>. Acesso em: 17 mai. 2012.
} 
Atala desenvolve um novo prato, DJ Marky produz a trilha, os irmãos Campana criam o design de uma poltrona, Hornest idealiza personagens nos muros da cidade. Todas essas expressões juntas, com a produção executiva de Fernando Meirelles e direção de Paulinho Caruso. No vídeo "Encontre-se em São Paulo", da mesma campanha, a protagonista, uma turista, passeia por pontos turísticos da cidade, como a Pinacoteca, a Estação Luz, o Mercado da Cantareira, o MASP, o Estádio do Pacaembu, uma loja de decoração, um bar com música ao vivo, durante o dia, e outros durante a noite, como sala São Paulo, ponte estaiada Octávio Frias de Oliveira, Teatro do Ibirapuera, um restaurante sofisticado e uma casa noturna, onde a protagonista encerra a noite dançando ${ }^{14}$.

\section{7. $O$ entretenimento e a identidade cultural da cidade}

O cinema, a música e a literatura também fornecem indícios sobre a importância do entretenimento para a formação da identidade cultural da cidade.

Um exemplo cinematográfico de como o entretenimento está incorporada à identidade cultural da cidade é o seriado (no formato telefilme) "Alice", com 13 episódios em 2008 e mais dois filmes de 90 minutos exibidos em 2010. Produzido pela Home Box Office (HBO) e Gullane Filmes, foi dirigido e roteirizado por Sérgio Machado e Karim Aïnouz. O seriado narra a história de Alice, representada pela atriz Andreia Horta, que levava uma vida pacata como guia turístico em Palmas, Tocantins, quando é obrigada a viajar para São Paulo, sua cidade natal, para resolver problemas decorrentes do processo de partilha da herança deixada pelo pai. A viagem seria breve, mas Alice se encanta com a cidade, particularmente com suas opções de entretenimento e decide ficar.

\footnotetext{
${ }^{14}$ Disponível em: $<$ http://www.youtube.com/watch?v=BG8hrsE992E\&feature=plcp $>$. Acesso em: 17 mai. 2012.
} 
Grande parte do seriado é ambientado em restaurantes, bares, cinemas, teatros, shows, exposições, casas noturnas que cumprem o papel de País das Maravilhas para a Alice paulistana. Os diretores escolheram como personagens os habitués desses lugares. Para Aïnouz, a história é um tipo de crônica, pois relata o dia a dia dos personagens típicos da cidade de São Paulo. "Como eles trabalham, como acordam, como dormem, como é a vida cotidiana deles. E isso tudo se mistura às aventuras que se pode viver em uma cidade como São Paulo".

A música também revela os elementos e as imagens que simbolizam e representam a cidade, dando sentido à sua identidade cultural (HALL, 2006). Um compositor em particular, Adoniram Barbosa, exemplifica, por meio de suas canções, a importância do entretenimento, particularmente o relacionado à vida noturna em São Paulo, nas décadas de 1950 e 1970, que se transformava física e culturalmente. No momento em que o trabalho, a velocidade e o progresso davam o tom na cidade, o entretenimento já

[...] exercia certo fascínio sobre as pessoas; era uma maneira de fuga das mazelas, de experimentar prazeres, de fugir do cotidiano cansativo e monótono da cidade. A vida boêmia, a efervescência cultural nos bares e botequins de São Paulo, tentava diminuir o ritmo que a cidade impunha aos seus moradores (SANTOS e DENCKER, 2008, p.21).

A obra de Adoniram Barbosa é uma narrativa da cidade que percorre o cenário de várias épocas, relatando as mudanças dos hábitos e costumes, descrevendo rituais e tradições de seus habitantes, destacando os traços e as singularidades da identidade cultural paulistana. Suas músicas ironizam o tão exaltado progresso, delatando as dificuldades dos que assistiam aos símbolos da cidade ou apenas a uma pobre, mas "Saudosa Maloca", sendo destruídos sob a justificativa da necessidade de modernização. 
Modernização que construía a cidade da velocidade, projetada para não parar, alertando para o desaparecimento da cidade pacata e o surgimento de uma cidade violenta e insegura (SANTOS e DENCKER, 2008, p. 24-5), como denuncia "Iracema": Iracema, fartavam vinte dias pra o nosso casamento / Que nóis ia se casar / Você atravessou a São João / Veio um carro, te pega e te pincha no chão.

O trabalho, que gerava o progresso, aparece em muitas de suas músicas como monótono e estafante também foi satirizado. Em "Conselho de Mulher", Deus parece concordar com o boêmio paulistano: Eu sempre iscuitei falar, que o pogressio vem do trabaio / Então amanhã cedo, nóis vai trabalhar / Quanto tempo nóis perdeu na boemia / Sambando noite e dia, cortando uma rama sem parar / Agora iscuitando o conselho das mulheres / Amanhã vou trabalhar, se Deus quiser, mas Deus não quer! [...]

Sua crítica à cidade do trabalho, da velocidade e do progresso usou a ruptura possibilitada pelo entretenimento, pela vida noturna, pelos hábitos dos boêmios, pela bebida, tema recorrente em suas letras - [...] Não me amole rapaz, não me amole / Não me amole, deixa de conversa mole / Agora não é hora de falar / Nós viemo aqui pra beber ou pra conversá? [...] - pela festa, pela roda de samba. As comemorações, os encontros, enfim, a sociabilidade engendrada nos espaços de entretenimento, como acontecia "No Morro da Casa Verde", contrapõem-se às amarguras da vida dos trabalhadores: Silêncio, é madrugada / No morro da casa verde / A raça dorme em paz / E lá embaixo / Meus colegas de maloca / Quando começa a sambá não para mais / Silêncio! / Valdir, vai buscar o tambor / Laércio, traz o agogô / Que o samba na casa verde enfezou! / Silêncio!

A literatura produzida em São Paulo também fornece indícios da importância do setor de entretenimento na identidade cultural da cidade. Como narrativa da cidade, a 
literatura capta o imaginário de sua população. Nela estão projetadas as fantasias, as emoções, os dramas que evidenciam a importância do entretenimento para sua identidade cultural.

Em 2010, o jornalista paulistano Daniel Piza publicou o livro "Noites Urbanas", com dez contos e dezoito minicontos, todos ambientados em São Paulo. Para o autor, cidade "é uma cornucópia de histórias ainda por contar" ${ }^{15}$, é o vaso repleto de personagens, situações, dramas, paixões, conflitos que inspiram músicos, escritores, cineastas e todos os cronistas que narram o cotidiano na metrópole paulista.

Piza produziu um sutil mapeamento dos sentimentos dos paulistanos, expressando-os por meio de analogias que revelam a indiferença, a frustração, o desamor e os múltiplos dilemas das pessoas que ao mesmo tempo odeiam e amam, aflorando tensões que geram simultaneamente a intensidade criativa e conflito social, vitalidade e melancolia. Não se trata apenas dos equipamentos e atividades de entretenimento como referência e cenário, ou como fonte para a criação de personagens e histórias. O autor usa as paisagens associadas às atividades de entretenimento da cidade como analogia para descrever os sentimentos de seus personagens, como se somente esse momento de lazer tivesse o poder de sintetizar com precisão e profundidade o que sentem os que vivem em São Paulo.

\section{Considerações finais}

Para responder ao problema proposto pela presente pesquisa, considerando a identidade como instável, não fixa, não permanente e acima de tudo múltipla, o primeiro passo foi assumir tal multiplicidade, o que ocorre no próprio problema de pesquisa, que afirma estar a identidade cultural de São Paulo em pleno processo de

\footnotetext{
${ }^{15}$ Disponível em: $<$ http://blogs.estadao.com.br/daniel-piza/convite-a-todos/>. Acesso em: 28 mai. 2012.
} 
transformação, questionando se essa transformação está incluindo o entretenimento como mais um elemento de sua identidade cultural, portanto, não excluindo outros elementos culturais identitários. O próximo passo foi levantar as múltiplas identidades da cidade, tarefa complexa devido às suas constantes transformações.

Transformações que fazem São Paulo não possuir um marco referencial estável para a definição de sua identidade, seja ele qual for. Sua população é multicultural, formada por imigrantes das mais variadas origens, que trouxeram suas referências religiosas, gastronômicas, estéticas, folclóricas etc. Sua economia é diversificada. A cidade ao longo de sua história foi agregando atividades que a tornaram um nó de integração entre agricultura, comércio e serviços, por consequência, São Paulo é identificada como centro financeiro, industrial, cultura, político, universitário, hospitalar. Sua arquitetura quase não possui vestígios de seu passado colonial ou imperial, seu processo de urbanização não permitiu a consolidação de marcos referenciais estáveis, condenando-a ser sempre nova. Sua identidade só pode ser apreendida e compreendida se considerada múltipla.

Mas como captar a multiplicidade de identidades da cidade diante da ausência de referenciais estáveis? A solução foi a análise de sua narrativa identitária. Para Hall (2006), a narrativa identitária permite captar a identidade em toda sua multiplicidade. Ela pode ser apreendida na história, na literatura, na música, na cultura popular e em outras manifestações culturais que assumem o papel de indícios, permitindo captar como a cidade é imaginada, descrita e apresentada, revelando suas múltiplas identidades.

Na perspectiva histórica, particularmente na conjuntura da "segunda fundação", que procurou sobrepor seu passado conflitivo e anárquico, diferenciar o ontem monótono e atrasado do hoje excitante e moderno, além de ressaltar as imagens 
consensuais, alguns elementos aparecem com muita força na narrativa da cidade. Velocidade, trabalho e progresso compuseram a narrativa identitária da cidade, relevando a matéria-prima da construção da identidade de São Paulo nesse período, transformando essas palavras em seus elementos essenciais. Mesmo a identidade sendo múltipla, fragmentada, pouco reconhecível e apreensível, sua imagem de locomotiva do Brasil, cidade que não para, capital do trabalho, ganhou relevo.

A análise da conjuntura histórica, a partir da "segunda fundação" da cidade revelou que o entretenimento também passou a compor a narrativa identitária de São Paulo, aparecendo como tema e cenário na literatura, ganhando colunas exclusivas nos jornais e revistas, promovendo o turismo na cidade, atestando que ele vem, em um longo processo, sendo incorporado aos hábitos de seus habitantes. Tal processo não foi alterado e, ao longo das décadas seguintes, o entretenimento ganhou cada vez mais relevância para a identidade cultural paulistana.

Os indícios quantitativos para sustentar essas constatações são significativos. $\mathrm{O}$ número no tempo presente de restaurantes, bares, salas de cinemas, teatros e peças encenadas, além da quantidade de revistas, colunas e cadernos de jornais, web sites, apps para smartphones, programas de rádio e televisão, são fortes indícios para comprovar que a fruição do entretenimento é parte dos hábitos dos paulistanos e da identidade cultural da cidade.

São Paulo possui múltiplas e variadas identidades, uma delas é a da cidade do entretenimento que, em conjunto com as demais, estão sobrepostas, como camadas não cristalizadas, que são reveladas por meio da análise sua narrativa identitária.

Diante do exposto, parece impossível não considerar a importância econômica, social e cultural do setor do entretenimento para a compreensão complexa da cidade. 
Ele está incorporado aos hábitos e costumes dos paulistanos, promove São Paulo como destino turístico, gera trabalho, renda e riqueza, é enredo cinematográfico, inspira compositores e escritores. Os argumentos aqui apresentados apontam que a fruição de entretenimento é cada vez mais significativa no cotidiano da cidade e de uma parcela considerável de sua população, transformando-se em setor de peso na economia da cidade e em uma referência capaz, no tempo presente, de ser mais um elemento da identidade cultural da cidade de São Paulo.

\section{Referências}

CANCLINI, N.G. Culturas híbridas: estratégias para entrar e sair da modernidade. 4. ed. São Paulo: Edusp, 2008.

Consumidores e cidadãos. 8. ed. Rio de Janeiro: Editora UFRJ, 2010.

CASTELLS, M. O poder da identidade. São Paulo: Paz e Terra, 1999.

D’ALESSIO, P. São Paulo cidade espetáculo: metrópole da diversidade brasileira. São Paulo: Editora Dialeto, 2008.

DEBORD, G. A sociedade do espetáculo. Rio de Janeiro: Contraponto, 2008.

FIGUEIREDO, A. C. de. Novo Dicionário da Língua Portuguesa. Rio de Janeiro: Livraria Clássica, 1913. Disponível em: <http://pt.scribd.com/doc/51527367/NovoDiccionario-da-Lingua-Portuguesa-Candido-de-Figueiredo-1913 > Acesso em: 08 mar. 2012.

FREIRE, L.O. Grande e novíssimo dicionário brasileiro da língua portuguesa. Rio de Janeiro: s.c.p., 1938. 5 v.

GABLER, N. Vida, o filme: como o entretenimento conquistou a realidade. São Paulo: Companhia das Letras, 1999.

GIOVANELLI, C. Nascimento e morte de uma balada. Revista Veja São Paulo, São Paulo, 10 ago. 2011. Disponível em: $<$ http://vejasp.abril.com.br/revista/edicao2229/nascimento-morte-de-uma-balada>. Acesso em: 10 ago. 2011.

HALL, S. A identidade cultural na pós-modernidade. 11.ed. Rio de janeiro: DP\&A, 2006. 
LIMENA, M.M.C. Cidades globais, cidades virtuais: a construção da identidade-lugar em tempos de incerteza. In: BORELLI, S. H. S.; FREITAS, R. F. (Org.). Comunicação, narrativas e culturas urbanas. São Paulo: EDUC; Rio de Janeiro: UERJ, 2009. p. 6377 .

LOMBARDI, M. Jovens deixam carreira em grandes empresas para investir em entretenimento. Universo On Line, São Paulo, 21 set. 2012. UOL Economia. Disponível em: $<\quad$ http://economia.uol.com.br/ultimasnoticias/redacao/2011/09/21/jovens-deixam-carreira-em-grandes-empresas-parainvestir-em-entretenimento.jhtm>. Acesso em: 21 set. 2012.

LOVE, J. A locomotiva: São Paulo na federação brasileira, 1889-1937. Rio de Janeiro: Paz e Terra, 1982.

MAGNANI, J. G. C.; SOUZA, B. M. (Org.). Jovens na metrópole. Etnografias de circuitos de lazer, encontro e sociabilidade. São Paulo: Editora Terceiro Nome, 2007.

MIRANDA, J.M. Ciclos de produção e cadeias produtivas na cultura. In: PRESTES FILHO, L.C.; CAVALCANTI, M.C. Economia da cultura: a força da indústria cultural no Rio de Janeiro. Rio de Janeiro: E-papers, 2002.

MORAES, E.J. A brasilidade modernista: sua dimensão filosófica. Rio de Janeiro: Graal, 1986.

MORAES SILVA, A.M. Diccionario de Lingua Portugueza. Lisboa: Typographia Lacerdina, $1813 . \quad$ Disponível em: < http://books.google.com.br/books?id=hXr_KN0PfCcC\&printsec=frontcover\&hl=pt$\mathrm{BR} \&$ source $=\mathrm{gbs}$ ge summary $\mathrm{r} \& \mathrm{cad}=0 \mathrm{\# \textrm {v }}=$ onepage $\& \mathrm{q} \& \mathrm{f}=$ false $>$. Acesso em: 08 mar. 2012.

PINTO, Z.A. (Org.) História e personagens: Cadernos Paulistas. São Paulo: Imprensa Oficial, Editora SENAC, 2002.

PIZA, D. Noites Urbanas: contos. Rio de Janeiros: Bertrand Brasil, 2010.

QUEIROZ, M.I.P. de. Ufanismo paulista. Revista USP, São Paulo: Universidade de São Paulo, n.13, p.78-87, 1998.

RODRIGUES, L. Overnight. Folha de São Paulo, São Paulo, 15 abr. 2012. Revista São Paulo, p.35.

SALIBA, E.T. Histórias, memórias, tramas e dramas da identidade paulistana. In: PORTA, P. (Org.) História da cidade de São Paulo: a cidade na primeira metade do século XX. São Paulo: Paz e Terra, 2004. v.3, p.555-587.

SANTOS, L.O.S. e DENCKER, A.F.M. São Paulo dá samba: visão da hospitalidade por meio do olhar de Adoniran Barbosa. Revista Hospitalidade, São Paulo, ano V, n. 1, p.13-30, jun. 2008. 
SÃO PAULO. São Paulo Turismo. Plano de turismo municipal - cidade de São Paulo. São Paulo: Spturis/Prefeitura de São Paulo, 2010.

SEVCENKO, N. Orfeu extático na metrópole: São Paulo, sociedade e cultura nos frementes anos 20. São Paulo: Companhia das Letras, 1992.

. Rio de Janeiro y San Pablo: desarrollo social y cultural comparativo, 19001930. In: HARDOY, J. e MORSE, R. (Org.) Nuevas perspectivas em los estúdios sobre historia urbana latinoamericana. Buenos Aires: Instituto Internacional de Medio Ambiente y Desarrollo, 1989, 149-157.

RODRIGUES, L. Overnight. Folha de São Paulo, São Paulo, 15 abr. 2012. Revista São Paulo, p.35.

TOLEDO, R.P. A capital da solidão: uma história das origens de São Paulo a 1900. Rio de Janeiro: Objetiva, 2003.

TRIGO, L.G.G. Entretenimento: uma crítica aberta. São Paulo: Editora SENAC, 2008.

VEAL, A.J. Metodologia de pesquisa em lazer e turismo. São Paulo: Aleph, 2011.

\section{Endereço do Autor:}

Alexandre Leonarde

Escola de Artes, Ciências e Humanidades da Universidade São Paulo.

Av. Arlindo Béttio, 1000, Ermelino Matarazzo

São Paulo - SP - 03828-000

Endereço Eletrônico: leonarde@usp.br 